\title{
CONSTRUCTION OF INFORMATION SYSTEMS OF KNOWLEDGE FORMATION ON THE BASIS OF SERVICE-ORIENTED ARCHITECTURE USING NEURAL NETWORKS
}

\author{
Murad OMAROV ${ }^{1}$, Vusala MURADOVA ${ }^{2, *}$ \\ ${ }^{1}$ Department of Natural Sciences, Kharkiv National University of Radio Electronics, Kharkiv, Ukraine \\ ${ }^{2}$ Department of Natural Sciences, Kharkiv National University of Radio Electronics, Kharkiv, Ukraine
}

\begin{abstract}
The subject of research is the design and development of information systems and management processes of knowledge formation. Objective is to analyze the modern information technologies and service-oriented systems used to organize and control the processes of formation of knowledge as well as practical and methodological approaches used in these technologies. The following tasks are solved in the article: development of information technology, organization and management of the processes of knowledge formation on the basis of methods and models of service-oriented systems. This technology is based on the functional requirements of the processes of knowledge formation. The following results were obtained: The relevance of the scientific objectives was analyzed. The results of the analysis of the modern models, methods and information technologies in processes of knowledge formation confirmed the need for the development of information technology processes control the formation of knowledge, which will improve the effectiveness of decisions. It was identified that this technology needs to be developed based on the service oriented architecture.
\end{abstract}

Conclusions: The information technology management processes of knowledge formation based on service-oriented architecture with the use of new methods and models of processes of formation of knowledge was developed.

Keywords: Information technology, Service-oriented systems, Knowledge formation

\section{INTRODUCTION}

Information technologies (IT) are intensively used all over the world in the various fields and it is almost impossible to do without their use. In modern conditions, the problem of implementing information technology in the field of education is relevant. An integral part of this process is the creation of new and improvement of existing systems of the process of knowledge formation.

Modern economics, science and other spheres of human activity require highly qualified specialists in various fields of knowledge. Therefore, the urgent task is to form a specialist knowledge system. Distance learning is one of the areas in knowledge creation. It has its own specifics and, in some situations, is the most effective form of process of knowledge. Managing the process of knowledge creation can be implemented on the basis of information technology.

Service oriented architecture (SOA) is a new direction in a building of the corporate automated information systems and is specifically designed for integration multi-platform applications supporting business processes in manufacturing [1]. Service - oriented architecture arose from the need to create reliable it services across the enterprise can be centrally coordinated.

Service-oriented architecture arose from the need to create reliable IT services that can be centrally coordinated throughout the enterprise[2,3]. As a rule, this responsibility is assigned to information technology departments. Technological architecture defines a set of principles and standards (industry

*Corresponding Author: viusalia.muradova@nure.ua

Received:11.10.2019 Published: 16.12.2019 
standards; standards related to products; configurations) that provide guidance on the selection and use of technologies such as hardware platforms, operating systems, database management systems, development tools, programming languages, middleware layers, email services, directories, security systems, network infrastructure, etc. Certain aspects (security, integration, sometimes development) can be distinguished into separate areas (domains) of the enterprise architecture, depending on the characteristics of the organization.

\section{ANALYSIS OF THE PROBLEM AND EXISTING METHODS}

In this area four types of subjects are involved: student (trainee), tutor, teacher and manager. The student is the person whose knowledge is formed. A tutor is a subject that controls the process of forming the knowledge of a particular student.

A teacher is a subject who forms teaching materials for the process of knowledge formation in a specific subject area. The manager is the subject of the task, which includes the organization and management of the process of knowledge formation for many students (trainees), tutors and teachers.

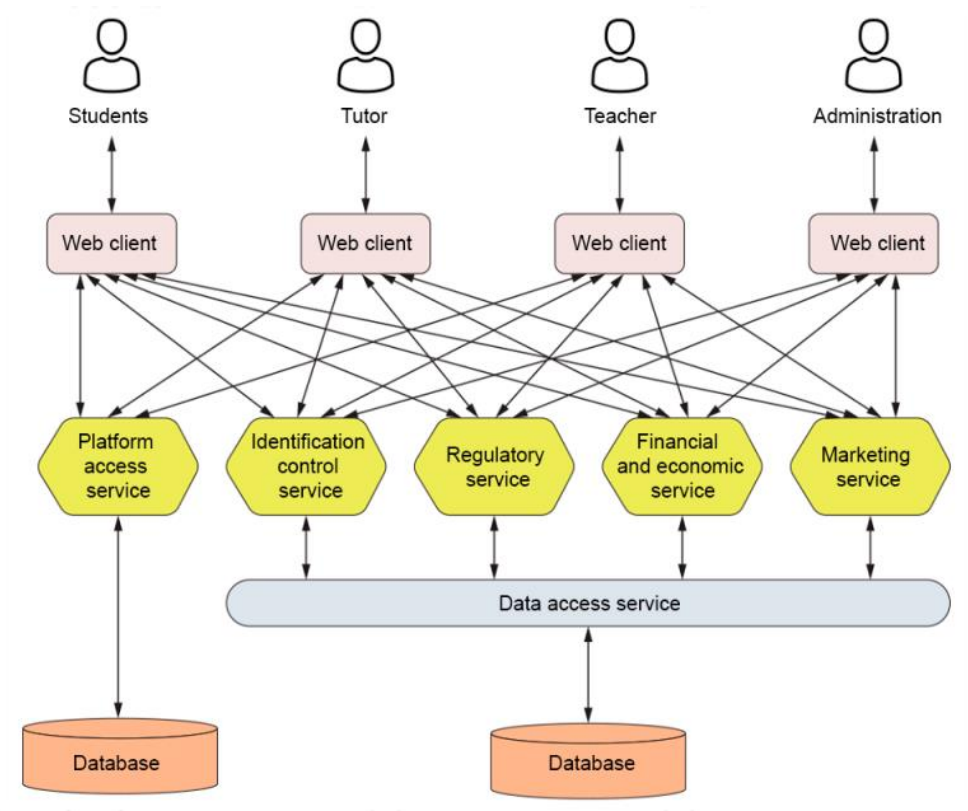

Figure 1. Information technology model of knowledge management processes

A tutoring agent should find students who have recently been enrolled in training and have not undergone initial training. After receiving the list of these students, the tutor should be able to send students the primary instruction from this list. In addition, the tutor should be able to get a list of students to whom the instruction has already been sent, but no confirmation of reading has been received from the student. The tutor should be able to re-send the initial briefing. Also, the tutor should have access to questions posed by students regarding initial instruction. If the question is asked in the already formed database of answers, the tutor should be able to use the answer already in the database for sending to students. If the question is new and the tutor considers that his competence is sufficient for the answer, he (the tutor) should formulate the answer and send it to the specialist for examination according to the primary instruction. The tutor should send the student the answer received from the specialist, and the question-answer pair should be entered into the database. 


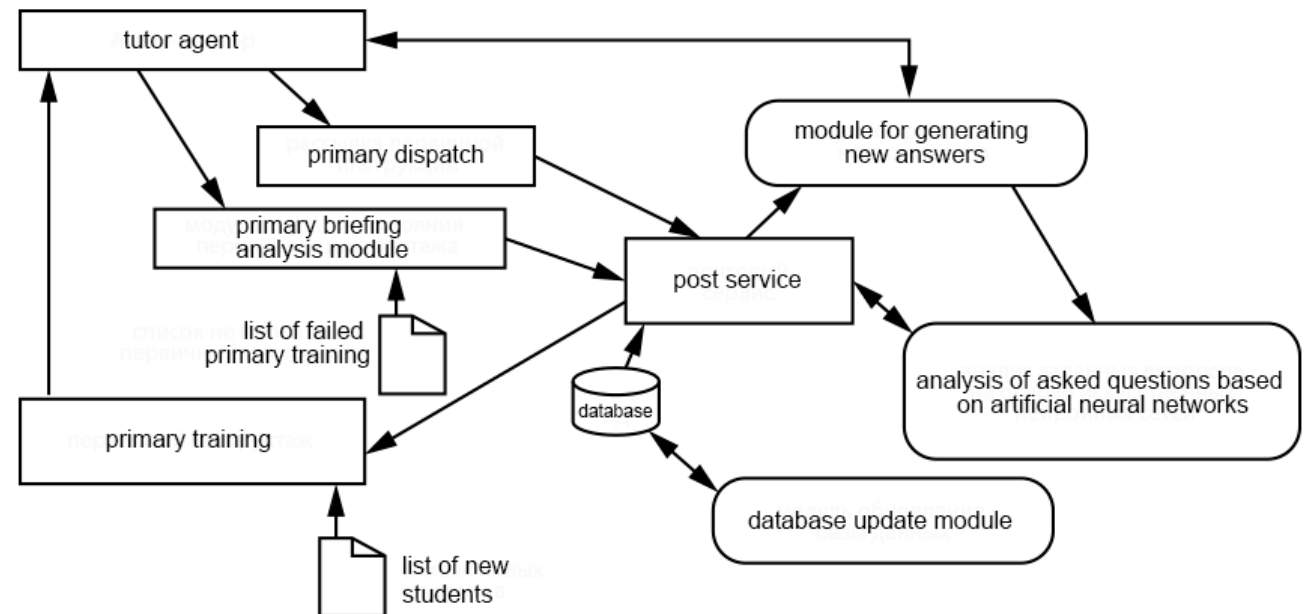

Figure 2. The block diagram of the agent-tutor

Artificial neural networks are a system of connected and interacting simple processors (artificial neurons). Such processors are usually quite simple (especially compared to the processors used in personal computers). Each processor of such a network deals only with the signals that it periodically receives and the signals that it periodically sends to other processors. And, nevertheless, being connected to a sufficiently large network with controlled interaction, such individually simple processors together are capable of performing rather complex tasks. Neural networks are not programmed in the usual sense of the word, they are trained. Learning ability is one of the main advantages of neural networks over traditional algorithms. Technically, training consists in finding the coefficients of connections between neurons. In the learning process, the neural network is able to identify complex relationships between input and output, as well as perform generalization. This means that if training is successful, the network will be able to return the correct result based on data that were not in the training sample, as well as incomplete and / or "noisy", partially distorted data.

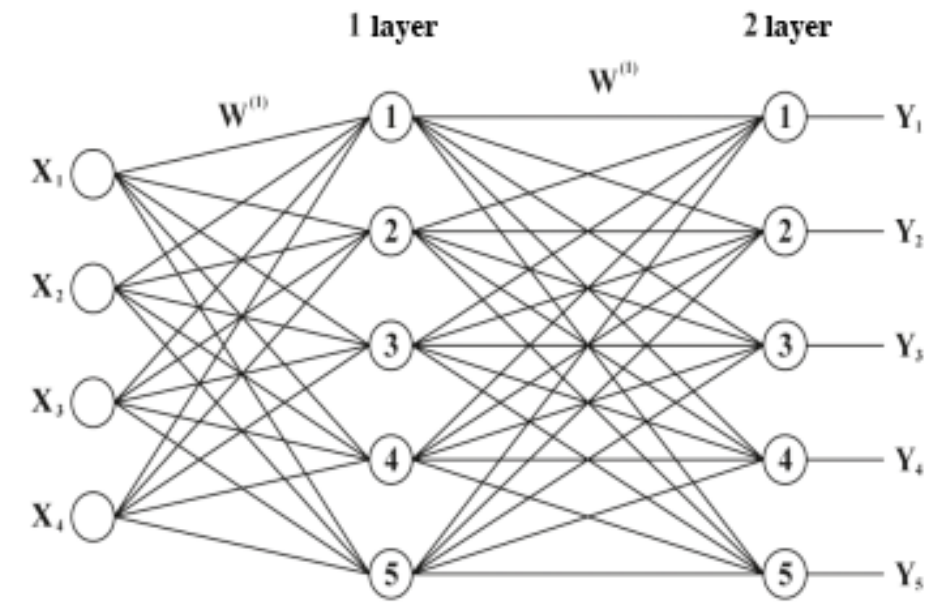

Figure 3. The behavior model of students based on a two-stage neural network 
According to the beginning of the 1st semester, the objective of the PS model is to give a forecast of its state at the end of the 1st semester and a forecast for the 2 nd semester. Therefore, the model is built as a two-stage neural network. This means that the output of the first layer, which is the forecast for the end of the first semester, is fed to the input of the second layer as an input signal for building a forecast for the 2nd semester. The network was trained using the Hebb method, similar to the network training discussed earlier. The weight matrix for this two-stage neural network is much more cumbersome, so we do not give it. A model that allows, based on the assessment of the current performance of students, to predict the integrated performance (based on an artificial neuron).

A model of information technology for managing knowledge formation processes has been built, which allows increasing the efficiency of decisions. A block diagram of the agent-tutor work has been developed, which allows you to display the business processes in which the tutor is involved. This scheme is based on the job descriptions of the tutor and is made in accordance with the serviceoriented architecture.

A model of student behavior based on a two-stage neural network is constructed, which allows predicting integrable performance on the basis of an artificial neuron. This model is necessary to improve the quality of decisions, because it allows you to predict the behavior of the student.

\section{REFERENCES}

[1] Omarov M, Muradova V. J. Scientific Notes of the Azerb. Technic. Univer. 2016, 3, 204-214.

[2] Биберштейн Н., Боуз С. Компас в мире сервис-ориентированной архитектуры (SOA). M.: Кудиц Пресс, 2007. 228 с.

[3] Шаппелл Д.А. ESB - Сервисная Шина Предприятия. - СПб.: БХВ Петербург, 2008. 347 с. 